\title{
U.S. Latino Leaders Versus the GLOBE's Latin American and Anglo Cluster
}

\author{
Karina Gil ${ }^{1}$ \\ ${ }^{1}$ Worden School of Social Service, Our Lady of the Lake University, San Antonio, Texas, United States \\ Correspondence: Karina Gil, Worden School of Social Service, Our Lady of the Lake University, 411 SW 24th \\ Street, San Antonio, Texas, 78207, United States.
}

Received: July 29, 2019

Accepted: September 11, 2019

Online Published: September 16, 2019

doi:10.5539/ibr.v12n10p38

URL: https://doi.org/10.5539/ibr.v12n10p38

\begin{abstract}
The current study compares the leadership preferences among Latino leaders in the U.S. and the GLOBE's Latin American and Anglo Clusters. The study was done with a national sample size of 188 Latino leaders from all over the U.S. The surveying instrument used was sections 2 and 4 of the Alpha form of The Global Leadership and Organizational Behavior Effectiveness Questionnaire (GLOBE) by House et al. (2004) and a demographic survey developed by the researcher. $t$-Tests were used to compare the overall mean score of the research sample with the grand mean score of both the Latin American and Anglo clusters. Results indicate that Latino leaders in the U.S. had different leadership preference than the GLOBE's Latin American and Anglo cluster. One of the main contributions of the research to the body of knowledge is that it brings to light the uniqueness of the Latino leadership preferences and shows how dissimilar their preference is from the Latin American and Anglo Clusters of the GLOBE.
\end{abstract}

Keywords: Hispanic or Latino leadership, GLOBE, leadership preferences

\section{Introduction}

Hispanics or Latinos (the terms will be used interchangeably throughout this document) have experienced unprecedented growth that permeates all facets of the U.S. socio-economic and political life. According to the U.S. Census Bureau, there are 50.5 million Hispanic adults in the United States (U.S. Census Brief, 2011). Hispanics or Latinos represent $16 \%$ of the total population of the U.S. (U.S. Census Brief, 2011) thus solidifying themselves as the second largest group (Martinez \& Ariosto, 2011). Latinos are also recognized as the fastest-growing group, which is generally explained due to the young nature of the Hispanic community, with almost half of Latinos being under the age of 25 (National Council of La Raza, 2004), and representing 20.8\% of the millennial generation (Frey, 2018).

Additionally, Latinos are a very diverse group with $63 \%$ being Mexican Americans, 9.2\% being Puerto Rican, 3.5\% being Cuban, 2.8\% being Dominican, $7.9 \%$ being Central American, 5.5\% being South American, and 6.8\% being all other Hispanics (U.S. Census Report, 2011). Although Latino's represent only 4 percent of the executive office positions on the Fortune 500 firms (Hispanic Association of Corporate Responsibility, 2016), as their numbers grow, Latinos will be moving more into leadership positions in traditional and non-traditional arenas thus making it imperative for researchers to learn more about this particular population.

\section{Literature Review}

\subsection{Leadership and Latinos}

Despite the unprecedented growth of the Latino community in the U.S., there continue to be gaps in the literature when it comes to the study of leadership. In fact, limited research has been conducted addressing leadership preferences as measured by the Global Leadership and Organizational Effectiveness (GLOBE) (House, Hanges, Javidan, Dofman, \& Gupta, 2004) questionnaire on Latino leaders in the U.S., and the research that has been done, tends to be qualitative in nature and conducted through informal surveys and focus groups.

Hernandez and Ramirez (2001) conducted a survey with Latinos in different states across the U.S. to explore their perspectives on leadership preferences. The survey found that Latinos expected their leaders to have four main characteristics that included character, competence, compassion, and community servanthood. Similarly, the survey found that it was important for Latinos, as compared to non-Latino groups, that the personality of the 
leaders included these traits. These findings were similar across all Latino subgroups including Latino women.

Other studies found a significant relationship between Latinos born outside the United States and a preference for Laissez-faire leadership styles (Teneyuca, 2005; Baumeister, 2006), with Mexican Americans showing a stronger preference for transactional leadership styles (Baumeister, 2006). Interestingly, a study conducted to draw comparisons between transformational and transactional leadership styles for U.S. and Latin American citizens found that both Latin American citizens and American women scored higher on transformational leadership than their male counterparts (Ramirez, 2002).

\subsection{GLOBE Overview}

Global Leadership and Organizational Behavior Effectiveness Study: Culture, Leadership, and Organizations: The GLOBE Study of 62 Societies (GLOBE) (House et al., 2004) is a 10-yearlong study that included 17,300 middle managers of 951 organizations in 62 societies in the industries of finance, food processing, and telecommunications. The GLOBE's theoretical framework was based on Hofstede's culture theory, strategic contingency theory, implicit leadership theory expanded to the cultural level, and McClelland's achievement theory of human motivation. To collect the data, two types of surveys were developed; the Alpha survey, which measured leadership effectiveness and organizational culture, and the Beta survey, which measured leadership effectiveness and societal culture. All instruments were applied by native investigators who were intimately familiar with the culture targeted.

Additionally, the GLOBE developed leadership dimensions across 10 cultural clusters by following culturally implicit leadership theory (CLT) and identified three overarching attributes of leadership effectiveness: universally desirable, universally undesirable, and culturally contingent. Of the 10 cultural clusters, 10 countries belonged to the Latin American cluster and included Argentina, Bolivia, Brazil, Colombia, Costa Rica, Ecuador, El Salvador, Guatemala, Mexico and Venezuela, while seven countries belonged to the Anglo cluster and included Australia, Canada (English Speaking), England, Ireland, New Zealand, South Africa (White sample) and the United States. The leadership survey of the GLOBE consisted of 112 questions that inquire about behaviors reflecting both societal and organizational cultures.

The GLOBE also identified 21 dimensions of what is considered to be outstanding leadership characteristics. These characteristics were factorial analyzed into a culturally endorsed implicit leadership theory (CLT) and were later merged, which created an end product of six globally identified leadership dimensions: Charismatic/Value-Based leadership, Team-Oriented leadership, Participative leadership, Humane-Orientation leadership, Autonomous leadership, and Self-Protective leadership.

\subsection{The GLOBE's Leadership Dimensions, and the Latin American and Anglo Clusters}

Table 1 depicts the CLT leadership profiles of the Latin American and Anglo Clusters. An Analysis of Variance (ANOVA) was performed to determine if cultures and cluster differ from the CLT leadership dimensions. Results indicated that cultures and clusters differ with respect to the six CLT leadership dimension $(p<.01)$ (House et al., 2004, p. 680).

Table 1. Leadership CLT Scores for Societal Clusters

\begin{tabular}{lcccccc}
\hline $\begin{array}{l}\text { Societal } \\
\text { Cluster }\end{array}$ & \multicolumn{5}{c}{ CLT Leadership Dimensions } \\
\cline { 2 - 7 } & $\begin{array}{c}\text { Charismatic/Value } \\
\text { Based }\end{array}$ & $\begin{array}{c}\text { Team- } \\
\text { Oriented }\end{array}$ & Participative & Humane-Oriented & Autonomous & Self-Protective \\
\hline Latin & 5.99 & 5.96 & 5.42 & 4.85 & 3.51 & 3.62 \\
America & 6.05 & 5.74 & 5.73 & 5.08 & 3.82 & 3.08 \\
Anglo & 5 & & & & & \\
\hline
\end{tabular}

Note. From Culture, Leadership, and Organizations: The GLOBE Study of 62 Societies (p. 680), by R. J. House, P. J. Hanges, M. Javidan, P. W. Dorfman, and V. Gupta, 2004, Thousand Oaks, CA: Sage Publications, Inc. Reprinted with permissions.

According to House et al. (2004), "many leadership attributes are culturally contingent" (p. 40); therefore, the culture in which a person is born has a significant influence in the way he or she may lead. The Latin American cluster included the largest number of cultures in the GLOBE sample, and when clustered together, Latin American countries scored high on charismatic/value-based $(M=5.99)$, team-oriented leadership $(M=5.96)$, medium on participative leadership $(M=5.42)$ and Humane-Oriented leadership $(M=4.45)$, and lowest on autonomous leadership $(M=3.51)$ and self-protective leadership $(M=3.62)$. Team-oriented leadership was 
positively correlated with institutional collectivism values $(r=.26, p<.05)$ and in-group collectivism practices $(r=.30, p<.05)$ and values $(r=.37, p<.01)$. Furthermore, charismatic-value based leadership was positively correlated with in-group collectivism values $(r=.32, p<.05)$. It is interesting to note that the Anglo cluster, to which the United States is a part, also scored high on charismatic leadership $(M=6.05)$, medium on team-oriented $(M=5.74)$, participative leadership $(M=5.73)$, and humane-oriented leadership $(M=5.08)$, and lowest on self-protective leadership $(M=3.08)$. However, it is important to keep in mind that the Latin American cluster was neither the lowest nor the highest in any of the aforementioned leadership dimensions. Based on the results of the Latin American cluster, House et al. (2004) stated that "for the Latin American cluster, an exemplar of effective leadership would be a person who practices charismatic/value-based and team-oriented leadership and would not be averse to some elements of self-protective leadership" (p. 687).

Furthermore, each Latin American country, as an individual society, was also measured on the GLOBE's leadership dimensions as was the United States. Table 2 depicts the Latin American and Anglo Cluster with each country showed individually.

Table 2. Leadership CLT Scores for Societal Cultures of Latin America and Anglo Cluster

\begin{tabular}{|c|c|c|c|c|c|c|c|}
\hline \multirow[b]{2}{*}{$\begin{array}{l}\text { Societal } \\
\text { Cluster }\end{array}$} & \multicolumn{7}{|c|}{ CLT Leadership Dimensions } \\
\hline & Country & $\begin{array}{c}\text { Charismatic } \\
\text { / } \\
\text { Value-Based }\end{array}$ & $\begin{array}{l}\text { Team- } \\
\text { Oriente } \\
\text { d }\end{array}$ & $\begin{array}{c}\text { Participativ } \\
\text { e }\end{array}$ & $\begin{array}{c}\text { Humane-Oriente } \\
\mathrm{d}\end{array}$ & $\begin{array}{c}\text { Autonomou } \\
\text { s }\end{array}$ & $\begin{array}{c}\text { Self-Protectiv } \\
\mathrm{e}\end{array}$ \\
\hline & Argentina & 5.98 & 5.99 & 5.89 & 4.70 & 4.55 & 3.45 \\
\hline Latin & Bolivia & 6.01 & 6.10 & 5.29 & 4.56 & 3.92 & 3.83 \\
\hline Americ & Brazil & 6.00 & 6.17 & 6.06 & 4.84 & 2.27 & 3.49 \\
\hline $\mathrm{a}$ & Colombia & 6.04 & 6.07 & 5.51 & 5.05 & 3.34 & 3.37 \\
\hline & Costa Rica & 5.95 & 5.81 & 5.54 & 4.99 & 3.46 & 3.55 \\
\hline & Ecuador & 4.46 & 6.21 & 5.51 & 5.13 & 3.53 & 3.62 \\
\hline & El Salvador & 6.08 & 5.95 & 5.40 & 4.69 & 3.47 & 3.43 \\
\hline & Guatemala & 6.00 & 5.94 & 5.45 & 5.00 & 3.37 & 3.77 \\
\hline & Mexico & 5.66 & 5.74 & 4.64 & 4.72 & 3.86 & 3.86 \\
\hline & Venezuela & 5.72 & 5.62 & 4.88 & 4.85 & 3.39 & 3.81 \\
\hline Anglo & Australia & 6.09 & 5.81 & 5.71 & 5.10 & 3.95 & 3.05 \\
\hline & Canada & 6.15 & 5.84 & 6.09 & 5.20 & 3.65 & 2.96 \\
\hline & Ireland & 6.08 & 5.81 & 5.64 & 5.06 & 3.95 & 3.00 \\
\hline & New Zeland & 5.87 & 5.44 & 5.50 & 4.78 & 3.77 & 3.19 \\
\hline & South Africa & 5.99 & 5.80 & 5.62 & 5.33 & 3.74 & 3.19 \\
\hline & $\begin{array}{l}\text { United } \\
\text { Kingdom }\end{array}$ & 6.01 & 5.71 & 5.57 & 4.90 & 3.92 & 3.04 \\
\hline & United States & 6.12 & 5.80 & 5.93 & 5.21 & 3.75 & 3.15 \\
\hline
\end{tabular}

Note. Replicated partially from From Culture, Leadership, and Organizations: The GLOBE Study of 62 Societies (p. 713), by R. J. House, P. J. Hanges, M. Javidan, P. W. Dorfman, and V. Gupta, 2004, Thousand Oaks, CA: Sage Publications, Inc. Reprinted with permissions.

\section{Problem Statement and the Purpose of the Study}

As the shifts in demographics indicate, Latinos are soon to become the largest minority group in the U.S. and will continue to climb the leadership ladder in multiple fields. Therefore, it is imperative to understand their leadership preferences, and how they compare to others. This is important as the U.S. prepares for a possible wave of unique leaders that will set the tone for the national norm that will permeate to a wide range of leadership positions.

This study seeks to compare the leadership preferences among national Latino leaders in the U.S. and the GLOBE's Latin American and Anglo Cluster. The main research question investigated is: Do Latino leaders in the U.S. score closely to the GLOBE's Latin American Cluster or Anglo Cluster?

\section{Methodology}

\subsection{Participants}

The GLOBE Phase 2 Alpha Questionnaire sections two and four were available for public use via a web-enabled anonymous survey tool. Participants were attained in two ways; formal and informal contacts. Through the formal contact, participants from the UnidosUS (formerly known as the National Council of La Raza) leadership, management, and affiliate executive directors were recruited. Through the informal contact, participants were 
recruited by informal networking with local and national Latino organizations and Latino-targeting/serving organizations, and by using professional networking sites and blogs.

The number of participants consisted of $(\mathrm{N}=188)$ out of which 87 were females, 100 were males, and one person was unknown. All participants self-identified as Latino or Hispanic and held a range of leadership positions. The mean age was 46.19. Regarding leadership positions, most participants indicated they held upper management positions; President $(n=46)$ at $28.2 \%$, Vice-President $(n=15)$ at $9.2 \%$, Director $(n=39)$ at $23.9 \%$, Owner $(n=$ $6)$ at $3.7 \%$, Manager/Supervisor $(n=36)$ at $22.1 \%$. Additionally, most participants indicated to be working in the non-profit sector $(n=73)$ at $41 \%$, followed by Education $(n=29)$ at $16.3 \%$, Health Care $(n=18)$ at $10.1 \%$, Entrepreneur/Small Business Owner $(n=25)$ at 14\%, Industrial/Manufacturing/Research Facility $(n=17)$ at $9.6 \%$, Government/Military $(n=14)$ at $7.9 \%$, Construction $(n=2)$ at $1.1 \%$, and there were some that did not report their industry $(n=10)$.

\subsection{Instruments}

This research used the GLOBE Phase 2 Alpha Questionnaire sections two and four, and a researcher-developed demographic survey. On the GLOBE Phase 2 Alpha Questionnaire sections two and four, respondents rated items on seven leadership preferences, 48-point Likert-type scale section two and 56 point Likert-type scale for section four, from one (greatly inhibits) to seven (contributes greatly), with four considered as "having no impact." The questionnaire measured the relationships between the six global leadership behaviors and 21 subscales described by House et al. (2004). The reliability of the GLOBE instrument exceeds .85 for all scales.

\subsection{Research Design}

The main surveying instrument was the GLOBE Phase 2 Alpha Questionnaire sections two and four, which was paired with a demographic survey. The research design is a cross-sectional survey and exploratory. Additionally, all survey questions were self-reported by the volunteer participants in the sample, and response set biases was minimized by the transition between instruments.

One-sample $t$-Test was deemed to be the best statistical measure to answer the research question since the grand mean of the Latin American and Anglo cluster were known. Additionally, the grand means data met the t-tests assumptions: 1) the GLOBE Phase 2 Alpha Questionnaire, sections two and four, allowed for the data collected to follow a continuous or ordinal scale give the fact that the answers were numerically translated; 2) Samples were self-selected random sample; 3) the data results were normally distributed; 4) the GLOBE's sample size was large, and the study's sample size was represented of Hispanics in leadership positions, and 5) due to the sample size, there was homogeneity of the variance.

Therefore, one-sample $t$-Tests were used to compare the overall mean score of the research sample with the overall mean score of both the Latin American and Anglo clusters. The significance level was deemed to be appropriate at 0.05 two-tailed. Missing values were excluded for the particular variables.

\subsection{Procedures}

Participants were attained through formal and informal contacts. Through the formal contact, participants from the UnidosUS (formerly National Council of La Raza) leadership, management, and affiliate executive directors were recruited through email. The email directed them to a link to access an online development software site that contained the survey for this research. Through the informal contact, participants were recruited by informal networking with local and national Latino organizations and Latino-targeting/serving organizations, and by using professional networking sites and blogs. Participants received emails directing them to complete the surveys online development software site.

Once the participants accessed the survey, they were directed to review and approve a consent form. The form provided them with information about the research, potential benefits, and risks, statements of anonymity and confidentiality, and prompted them with the required agreement prior to completing the surveying instruments.

The principal investigator, who was granted permission to conduct the survey by the university's Internal Review Board (IRB) Committee, was responsible for the collection of the survey responses.

\section{Results}

\subsection{Overall GLOBE Scores}

The Global Leadership and Organizational Behavior Effectiveness (GLOBE) Phase 2 Alpha Questionnaire sections 2 and 4 by House et al. (2004) determined the participants' statistical mean rank differences for the six GLOBE Culturally Endorsed Implicit Leadership dimensions. 
Respondents had a choice of a seven-point Liker- scale in GLOBE's Alpha questionnaire to determine what characteristics contribute to outstanding leadership: 1 (greatly inhibits), 2 (somewhat inhibits), 3 (slightly inhibits), 4 (has no impact), 5 (contributes slightly), 6 (contributes somewhat), 7 (contributes greatly).

Table 3 describes the statistics and mean scores of the research sample on the GLOBE's six leadership dimensions. In descending order, the research sample scored higher on Charismatic/Valued-Based Leadership ( $M$ $=6.20)$, medium on followed by Humane-Oriented Leadership $(M=5.57)$, and Participative Leadership $(M=$ 5.05), and lowest on Team-Oriented Leadership $(M=4.61)$, Autonomous Leadership $(M=4.09)$ and Self-Protective Leadership $(M=3.43)$.

Table 3. Distribution of Research Sample Leadership Dimensions Scores

\begin{tabular}{|c|c|c|c|c|c|c|}
\hline & $\begin{array}{l}\text { Charismatic } \\
\text { Valued Based } \\
\text { Leadership }\end{array}$ & $\begin{array}{l}\text { Team-Oriented } \\
\text { Leadership }\end{array}$ & $\begin{array}{l}\text { Humane-Oriented } \\
\text { Leadership }\end{array}$ & $\begin{array}{l}\text { Participative } \\
\text { Leadership }\end{array}$ & $\begin{array}{c}\text { Autonomous } \\
\text { Leadership }\end{array}$ & $\begin{array}{l}\text { Self-Protective } \\
\text { Leadership }\end{array}$ \\
\hline Valid & 188 & 188 & 187 & 177 & 188 & 188 \\
\hline $\mathrm{N} \quad$ Missing & 0 & 0 & 1 & 11 & 0 & 0 \\
\hline Mean & 6.203 & 4.614 & 5.5767 & 5.0561 & 4.0949 & 3.4319 \\
\hline Median & 6.36 & 4.6 & 5.67 & 5.1 & 4.25 & 3.41 \\
\hline Mode & 5.86 & 4.53 & 6 & 5.1 & 3.25 & 3 \\
\hline Std. & & & & & & \\
\hline Deviation & 0.80983 & 0.47854 & 0.97801 & 0.72307 & 1.17369 & 0.71634 \\
\hline Variance & 0.656 & 0.229 & 0.956 & 0.523 & 1.378 & 0.513 \\
\hline Skewness & -4.083 & -0.915 & -1.862 & -0.627 & -0.056 & 0.798 \\
\hline $\begin{array}{l}\text { Std. Error of } \\
\text { Skewness }\end{array}$ & 0.177 & 0.177 & 0.178 & 0.183 & 0.177 & 0.177 \\
\hline Kurtosis & 21.381 & 8.492 & 6.464 & 1.038 & -0.592 & 1.25 \\
\hline $\begin{array}{l}\text { Std. Error of } \\
\text { Kurtosis }\end{array}$ & 0.353 & 0.353 & 0.354 & 0.363 & 0.353 & 0.353 \\
\hline
\end{tabular}

Copyright by Karina E Gil, Ph.D., MSW

\subsection{Comparison of leadership preference of research sample and the Latin American Cluster}

This research question concerns with the differences between the mean of this research and the grand mean for the GLOBE's Latin American cluster. Scores were obtained for the GLOBE's six leadership dimensions: Charismatic Value-Based, Team-Oriented, Participative, Humane-Oriented, Autonomous, and Self-Protective. A one-sample $t$-Test was computed for each of the leadership dimensions to determine whether there were significant differences between the research sample group and the GLOBE scores obtained for the Latin American Cluster. Below are the individual results for each of the leadership preference, and Table 4 provides the $t$-Test results of the mean comparison between the research sample and Latin American Cluster for all the leadership preferences.

Charismatic/Value-Based

One-Sample $t$-Test on Charismatic/Value-Based Leadership dimension showed $t(187)=3.607, p=.000$ for this research sample. There was a significant difference between this research sample and the Latin American Cluster grand mean score. The research sample $(M=6.20)$ showed a stronger preference for Charismatic/Value-Based Leadership than did the Latin American Cluster $(M=5.99)$.

Team-Oriented Leadership

One-Sample $t$-Test on Team-Oriented Leadership dimension showed $t(187)=-38.565, p=.000$ for this research sample. There was a significant difference between the research sample and the Latin American Cluster grand mean score. The research sample $(M=4.61)$ showed a lower preference for Team Oriented Leadership than did the Latin American Cluster $(M=5.96)$.

Participative Leadership

One-Sample $t$-Test on Participative Leadership dimension showed $t(176)=-6.696, p=.000$ for this research sample. There was a significant difference between this research sample and the Latin American Cluster grand mean score, as illustrated in Table 4. The research sample $(M=5.05)$ showed a lower preference for Participative Leadership than did the Latin American Cluster $(M=5.42)$. 


\section{Humane-Oriented Leadership}

One-Sample $t$-Test on Humane-Oriented Leadership dimension showed $t(186)=10.161, p=.000$ for this research sample. There was a significant difference between this research sample and the Latin American Cluster grand mean score. The research sample $(M=5.57)$ showed a higher preference for Humane-Oriented Leadership than did the Latin American Cluster $(M=4.85)$.

Autonomous Leadership

One-Sample $t$-Test on Autonomous Leadership dimension showed $t(187)=6.832, p=.000$ for this research sample. There was a significant difference between this research sample and the Latin American Cluster grand mean score. The research sample $(M=4.09)$ showed a stronger preference for Autonomous Leadership than did the Latin American Cluster $(M=3.51)$.

\section{Self-Protective Leadership}

One-Sample $t$-Test on Self-Protective Leadership dimension showed $t(187)=-3.601, p=.000$ for this research sample. There was a significant difference between this research sample and the Latin American Cluster grand mean score, as illustrated in Table 4. The research sample $(M=3.43)$ showed a lower preference for Self-Protective Leadership than did the Latin American Cluster $(M=3.62)$.

Table 4. Mean comparison between Research Sample and Latin American Cluster

\begin{tabular}{|c|c|c|c|c|c|c|c|}
\hline & \multirow[b]{2}{*}{$\mathrm{t}$} & \multirow[b]{2}{*}{ df } & \multirow[b]{2}{*}{$\begin{array}{c}\text { sig. } \\
\text { (2-tailed) }\end{array}$} & \multirow[b]{2}{*}{$\begin{array}{c}\text { Mean } \\
\text { Research } \\
\text { Sample }\end{array}$} & \multirow[b]{2}{*}{$\begin{array}{c}\text { Mean Latin } \\
\text { American } \\
\text { Cluster }\end{array}$} & \multicolumn{2}{|c|}{$\begin{array}{l}95 \% \text { Confidence Interval of } \\
\text { the Difference }\end{array}$} \\
\hline & & & & & & Lower & Upper \\
\hline $\begin{array}{l}\text { Charismatic /Value } \\
\text { Based }\end{array}$ & 3.607 & 187 & 0.00 & 6.2 & 5.99 & 0.0965 & 0.3295 \\
\hline Team-Oriented & -38.565 & 187 & 0.00 & 4.61 & 5.96 & -1.4148 & -1.2771 \\
\hline Participative & -6.696 & 176 & 0.00 & 5.05 & 5.42 & -0.4712 & -0.2567 \\
\hline Humane-Oriented & 10.161 & 186 & 0.00 & 5.57 & 4.85 & 0.5856 & 0.8678 \\
\hline Autonomous & 6.832 & 187 & 0.00 & 4.09 & 3.51 & 0.416 & 0.7537 \\
\hline Self- Protective & -3.601 & 187 & 0.00 & 3.43 & 3.62 & -0.2912 & -0.0851 \\
\hline
\end{tabular}

Copyright by Karina E Gil, PhD, MSW

\subsection{Comparison of Leadership Preference of Research Sample and the Anglo Cluster}

This research question concerns with the differences between the mean of this research sample and the grand mean for the GLOBE's Anglo cluster. Scores were obtained for the GLOBE's six leadership dimensions: Charismatic Value-Based, Team-Oriented, Participative, Humane-Oriented, Autonomous, and Self-Protective. One-sample $t$-Test were performed on each of the leadership dimensions to determine whether there were significant differences between the research sample mean scores and the GLOBE's grand mean scores obtained for the Anglo Cluster. Below are the individual results for each of the leadership preference, and Table 5 provides the $t$-Test results of mean comparison between Reseach Sample and Anglo Cluster for all the leadership preferences.

Charismatic/Value-Based

One-Sample $t$-Test on Charismatic/Value-Based leadership dimension showed $t(187)=2.591, p=.010$ for this research sample. There was a significant difference between this research sample and the Anglo Cluster grand mean score. The research sample $(M=6.20)$ showed a stronger preference for Charismatic/Value-Based than did the Anglo Cluster $(M=6.05)$.

Team-Oriented Leadership

One-Sample $t$-Test on Team-Oriented leadership dimension showed $t(187)=-32.261, p=.000$ for this research sample. There was a significant difference between this research sample and the Anglo Cluster grand mean score. The research sample $(\mathrm{M}=4.61)$ showed a lower preference for Team-Oriented Leadership than did the Anglo Cluster $(\mathrm{M}=5.74)$.

Participative Leadership

One-Sample $t$-Test on Participative Leadership dimension showed $t(176)=-12.400, p=.000$ for this research 
sample. There was a significant difference between this research sample and the Anglo Cluster grand mean. The research sample $(M=5.05)$ showed a lower preference for Participative Leadership than did the Anglo Cluster $(M=5.73)$.

\section{Humane-Oriented Leadership}

One-Sample $t$-Test on Humane-Oriented Leadership dimension showed $t(186)=6.945, p=.000$ for this research sample. There was a significant difference between this research sample and the Anglo Cluster grand mean score. The research sample $(M=5.57)$ showed a higher preference for Humane-Oriented Leadership than did the Anglo Cluster $(M=5.08)$.

Autonomous Leadership

One-Sample $t$-Test on Autonomous Leadership dimension showed $t(187)=3.211, p=.002$ for this research sample. There was a significant difference between this research sample and the Anglo Cluster grand mean score. The research sample $(M=4.09)$ showed a higher preference for Autonomous Leadership than did the Anglo Cluster $(M=3.82)$.

Self-Protective Leadership

One-Sample $t$-Test Self-Protective Leadership dimension showed $t(187)=6.735, p=.000$ for this research sample. There was a significant difference between this research sample and the Anglo Cluster grand mean. The research sample $(M=3.43)$ showed a higher preference for Self-Protective Leadership than did the Anglo Cluster $(M=3.08)$.

Table 5. Mean comparison between Research Sample and Anglo Cluster

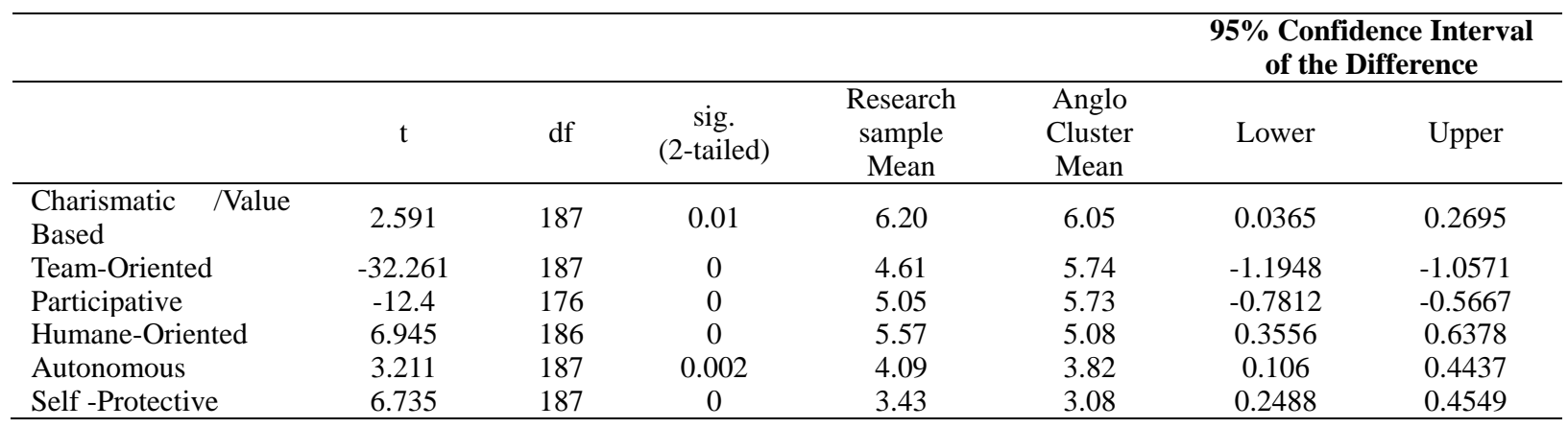

Copyright by Karina E Gil, Ph.D., MSW

\section{Discussion}

The premise behind this research came from House et al. (2004) which asserted "many leadership attributes are culturally contingent" (p. 40) which led to the expectation that Latino leaders in the U.S., whether they were U.S. native or foreign-born, would have similar, if not equal, scores to that of either the Latin American or Anglo cluster. This assertion was made because many Latinos in the U.S. continue to have strong ties to Latin American countries while acculturating to the Anglo culture to perform their leadership roles. However, when performing $t$-Tests to compare the mean differences, the study found significant differences between the research sample and both the Latin American and Anglo Cluster grand mean scores on all leadership dimensions.

Based on the GLOBE's scoring process and the mean scores of the research sample on the six leadership dimensions, the research sample found that Charismatic/Value-Based leadership contributes greatly to outstanding leadership practices, while Humane-Oriented and Participative leadership contributes slightly. The research sample also found that Team-Oriented and Autonomous Leadership did not have an impact on outstanding leadership practices, while Self-Protective was found to slightly inhibit it (See Figure 1). 


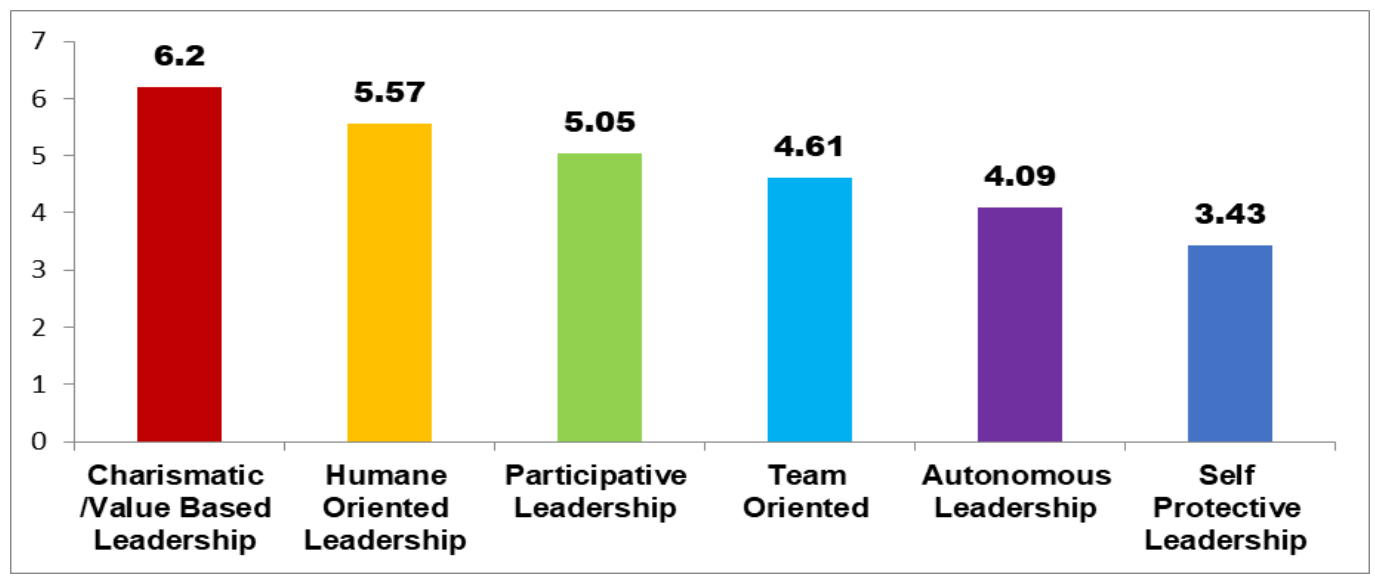

Figure 1. Bar Graph Study Group Mean Score on GLOBE’s Six Leadership Dimensions

Compared to the Latin American Cluster, in descending order, the research sample was found to have a higher preference for Charismatic/ Value-Based, Humane-Oriented and Participative Leadership practices, while the Latin American Cluster had a higher preference for Team-Oriented, Charismatic/Value-Based and Participative leadership practices. The research sample showed the least preference for Self-Protective leadership while the Latin American Cluster showed the least preference for the Autonomous Leadership practice

Although, both the research sample and the Anglo Cluster scored high on Charismatic/Value-Based leadership, the research sample showed an even higher preference for this leadership dimension than the Anglo cluster. Additionally, the Anglo Cluster showed a higher preference for Team-Oriented and Participative leadership than did the research sample. Both, the Anglo and research sample scored lowest on Self-Protective leadership but the Anglo Cluster showed an even lower preference for it.

These results are somewhat consistent with the results from Li (2010). Li studied the cultural and leadership preferences of Chinese petroleum professionals who grew up in mainland China and emigrated to the U.S. to achieve higher education. The study compared the global leadership preferences of the research sample and the reported Chinese and Anglo Cluster leadership scores in the GLOBE. Li found that her research sample was significantly different than China and the Anglo cluster on Team-Oriented, Humane-Oriented, Autonomous, and Self- Protective leadership. However, Li's study found no significant difference between the research group and the Anglo Cluster on Charismatic/ Value-Based leadership.

The fact that this research sample scored significantly different than the Latin American and Anglo cluster suggests the need for an alternative explanation. One possible explanation may be found in the concept of third culture or "hybrid team culture." Hybrid Culture, a term first used by Argentinean anthropologist Néstor García in his book Hybrid Cultures, is defined as "a process of intersections and transactions... which make it possible to avoid the segregation that accompanies multiculturalism and allows it to become inter-culturalism" (García, 2001). In line with this concept, the research sample, based on their leadership preference may have created an alternative culture based on professional identity rather than an ethnic identity. Additionally, this finding is somewhat consistent with the findings of the 2002 National Survey of Latinos conducted by the Pew Hispanic Center in partnership with the Keiser Family Foundation that indicated that "Hispanics seem to see themselves as having separate and distinct culture based in country of origin rather than sharing a single culture as Hispanics or Latinos" $(2002$, p.7). Instead of a culture based on country of origin, the research sample may have shared a culture based on achievement or a share experience of what may have taken them to achieve a high-level leadership position, thus making them have different preferences than either the Latin American or Anglo cluster.

Finally, based on their leadership preferences, it can be concluded that as a group, Latinos participant of this research study, prefer a leader who inspires, motivates and has strong core values, and who is supportive and considerate while exerting compassion and generosity. Latinos do not prefer a leader who uses status enhancements and face-saving tactics.

\section{Limitation of the Findings}

The limitations of the study included a sample of convenience, which limits the generalizability of the results. Most of the data were self-reported, which can be affected by self-perceptions, and most research participants 
worked in the non-profit sectors.

Additionally, all the questionnaires were administered in English only which limited the participants to those who were English speakers leaving behind an important percentage of community leaders who are Spanish speakers only.

\section{Implication and Recommendation for Future Research}

The Latino community is the fastest-growing minority group in the United States, and as such, its members are increasingly moving into leadership positions. Unfortunately, limited research has been conducted to learn more about Latino leadership practices and preferences. The present research attempted to contribute to the body of knowledge and bring to light the uniqueness of the Latino leadership preferences and experience. The findings indicate that this is a very different group within the Latino community, and more research is needed to explore the characteristics of this unique group.

Finally, it is essential to understand the findings of this research within its context in terms of culture and iterms of the current historical period. This research is being conducted while Latinos are about to become the largest minority group of the U.S. while still facing disadvantages in terms of income, education, and accessibility. The findings that the research group strongly preferred the leadership dimension of Charismatic/Value-Based leadership and Humane-Oriented leadership is very telling as to what Latino leaders prefer from political and sociological perspectives and points to what type of leaders they a looking for to bring their community's strength forth. Additionally, this should inform the theoretical and practice aspects of leadership, as this group appears to have unique views and, potentially, expectations when it comes to leadership preferences. The Latinos in this research study had clear expectations of the characteristics they prefer to see in their leaders. For leaders to gain the support and "buy-in" of this community, they will have to develop and amplify the characteristic preferred by this group. The growth of the Latino community has made it such that U.S. leaders can no longer ignore the preferences of this community. Therefore, a paradigm shift is imperative in leadership theory and practice so it can be adapted to reflect the needs and preferences of this community.

\section{References}

Baumeister, P. J. (2006). Implicit leadership theory in the United State: A comparative study of Mexican Immigrants, Mexican Americans, and non-Hispanic Americans. Dissertation Abstracts International, $66(8-\mathrm{B}), 4469$.

Frey, W. (2018). The Millenial Generation: A demographic bridge to America's diverse future. Metropolitan Policy at Brookings. Washigton: DC.

Garcia, N. (2001). Cultural hibridas. Estrategias para entrar y salir de la modernidad. Ramdom House: Mondadori.

Hernandez, A. \& Ramirez, A. (2001, January). Reflecting an American vista: The character and impact of Latino leadership. Latino Leadership, 1, 1. Washington, DC: National Community for Latino Leadership, Inc.

Hispanic Association on Corporate Responsibility. (2016). Corporate Inclusion Index. Washington: DC. Hispanic Association on Corporate Responsibility.

House, R., Hanges, P., Javidan, M., Dofman, P., \& Gupta, V. (Ed.). (2004). Culture, leadership, and organizations: the GLOBE study of 62 societies. California: Sage Publications, Inc.

Li, Y. (2010). A comparison of the cultural impacts of leadership preferences between overseas Chinese petroleum professionals and GLOBE scores. Ph.D. dissertation. San Antonio, TX: Our Lady of the Lake University. https://doi.org/10.2118/130654-MS

Martinez, M. \& Ariosto, D. (2011, March 24). Hispanic population exceeds 50 million, firmly nation's No. 2 group. $C N N$. Retrieved from http://articles.cnn.com/2011-03-24/us/census.hispanics_1_hispanic-population-illegal-immigration-foreignborn?_s=PM:US

National Council of La Raza. (2004). United States. (Fact Sheet). Washington, DC:Author.

Pew Hispanic Center/Kaiser Family Foundation. (2002). National Survey of Latino. Retrieved from http://pewhispanic.org/files/reports/15.pdf

Ramirez, R. (2002). A comparison if transformational and transactional leadership styles between United States and Latin American citizen as moderated by sex. Unpublished doctoral dissertation, Our Lady of the Lake University, Texas. 
Teneyuca, D. (2005). A study of the relationship between leadership style and language preference. Ph.D. dissertation. San Antonio, TX: Our Lady of the Lake University.

U.S. Census Bureau.(2011). The Hispanic population: 2010. 2010. Census Brief. Retrieved from http://www.census.gov/prod/cen2010/briefs/c2010br-04.pdf

\section{Copyrights}

Copyright for this article is retained by the author(s), with first publication rights granted to the journal.

This is an open-access article distributed under the terms and conditions of the Creative Commons Attribution license (http://creativecommons.org/licenses/by/4.0/). 